\title{
Targeting oncogenic miR-335 inhibits growth and invasion of malignant astrocytoma cells
}

\author{
Minfeng Shu ${ }^{\dagger}$, Xiaoke Zheng ${ }^{\dagger}$, Sihan $\mathrm{Wu}^{\dagger}$, Huimin Lu, Tiandong Leng, Wenbo Zhu, Yuehan Zhou, Yanqiu Ou, \\ Xi Lin, Yuan Lin, Dong Xu, Yuxi Zhou and Guangmei Yan*
}

\begin{abstract}
Background: Astrocytomas are the most common and aggressive brain tumors characterized by their highly invasive growth. Gain of chromosome 7 with a hot spot at 7q32 appears to be the most prominent aberration in astrocytoma. Previously reports have shown that microRNA-335 (miR-335) resided on chromosome 7q32 is deregulated in many cancers; however, the biological function of miR-335 in astrocytoma has yet to be elucidated.

Results: We report that miR-335 acts as a tumor promoter in conferring tumorigenic features such as growth and invasion on malignant astrocytoma. The miR-335 level is highly elevated in C6 astrocytoma cells and human malignant astrocytomas. Ectopic expression of miR-335 in C6 cells dramatically enhances cell viability, colonyforming ability and invasiveness. Conversely, delivery of antagonist specific for miR-335 (antagomir-335) to C6 cells results in growth arrest, cell apoptosis, invasion repression and marked regression of astrocytoma xenografts. Further investigation reveals that miR-335 targets disheveled-associated activator of morphogenesis 1(Daam1) at posttranscriptional level. Moreover, silencing of endogenous Daam1 (siDaam1) could mimic the oncogenic effects of miR-335 and reverse the growth arrest, proapoptotic and invasion repression effects induced by antagomir-335. Notably, the oncogenic effects of miR-335 and siDAAM1 together with anti-tumor effects of antagomir-335 are also confirmed in human astrocytoma U87-MG cells.
\end{abstract}

Conclusion: These findings suggest an oncogenic role of miR-335 and shed new lights on the therapy of malignant astrocytomas by targeting miR-335.

\section{Introduction}

Astrocytomas derived from astrocytes or astroglial precursors are the most common malignant cancer affecting the central nervous system, accounting for $>60 \%$ of primary brain tumors [1]. Current therapies for astrocytomas including surgery, radiation, and chemotherapy have not been successful due to the rapid and invasive tumor growth, the genetic heterogeneity and our poor understanding of the molecular mechanisms governing disease manifestation and progression [2].

MicroRNAs (miRNAs) are small non-coding RNAs (18 to 25 nucleotides) with potential roles in regulation of gene expression at posttranscriptional level [3]. Cumulative evidence suggests that deregulation of miRNAs may contribute to specific human diseases, including cancer. It

\footnotetext{
* Correspondence: guangmeiyan@gmail.com

+ Contributed equally

Department of Pharmacology, Zhongshan School of Medicine, Sun Yat-Sen University, Guangzhou, China
}

has been reported the amplification or overexpression of implicated microRNAs in cancers could materially serve as oncogenes [4]. Meanwhile, the tumor suppressing roles of certain miRNAs have also been presumed due to their physical deletion or reduced expression in human cancer [5]. Of note, recent data suggest an advantage of miRNAbased classification than mRNA profiling in origin identifying [6], novel biomarkers for diagnosis $[7,8]$ and prognosis predicting for cancer patients [9]. Even more, miRNAs stand for potential promising therapeutic targets for cancer treatment $[7,8,10,11]$. These findings provide new insights into the mechanisms of the tumor biology and give a novel thought to the therapeutic strategies

It is well established that chromosome $7 \mathrm{q} 32$ is a hot spot that frequently amplified in malignant astrocytomas [12]. There are 8 miRNAs(miR-593, miR-129-1, miR-335, miR-182, miR-96, miR-183, miR-29a, miR-29b-1) resided on this genomic locus, some of which have been investigated, either as oncogenes or tumor suppressor genes 
[13-15]. MiR-335, which is transcribed from the genomic region chromosome $7 \mathrm{q} 32.2$, has been reported to act as a tumor initiation and metastasis suppressor of breast cancer $[16,17]$. Furthermore, it is also demonstrated that miR-335 regulates $\mathrm{Rb} 1$ and controls cell proliferation in a p53-dependent manner [18]. In addition, a recent study has shown that miR-335 orchestrates cell proliferation, migration and differentiation in human mesenchymal stem cells [19]. These investigations indicate the important roles of miR-335 in tumor initiation and progression; however, the biological role of miR-335 in malignant astrocytoma pathogenesis is still largely unknown.

In this study, we aimed to investigate the possible contributions of miR-335 imbalance to astrocytoma pathogenesis. We found that miR-335 targeted a potential tumor suppressor Daam1 in astrocytoma cells, which promoted several malignant features such as growth and invasion, whereas miR-335 inhibition could potently induce growth arrest, apoptosis and invasion repression both in vitro and in vivo. These findings suggest an oncogenic role of miR-335 in the molecular etiology of malignant astrocytomas and might provide new insights into the implication for future cancer therapy.

\section{Materials and methods Cell Cultures and Patient Tissues}

Rat C6 astrocytoma cells and human U87-MG astrocytoma cells were obtained from the American Type Culture Collection. Human HEB normal astrocytes were obtained from Guangzhou Institutes of Biomedicine and Health, Chinese Academy of Sciences (Guangzhou, China). Cell cultures were performed as described previously [20]. Briefly, cells maintained in DMEM (Invitrogen, USA) supplemented with $10 \%$ FBS and a humidified atmosphere of $5 \% \mathrm{CO}_{2}$ at $37^{\circ} \mathrm{C}$. Rat normal astrocytes were obtained from Sprague-Dawley rat pups (postnatal 7 8 days). The first three passage astrocytes were used in our study. Tissue specimens (tumor, adjacent paracancerous tissues) of malignant astrocytoma patients were collected after informed consent and immediately frozen in liquid nitrogen. The astrocytoma tissues were verified by a pathologist as WHO grade II-III and the patients' characteristics were indicated in Additional file 1 Table S1.

\section{Cell Viability Assay}

Cell viability was determined by the 3-(4,5-dimethylthiazol-2-yl)-2,5-diphenyl tetrazolium bromide (MTT, Sigma, USA) assay. Briefly, cells were seeded in 96-well plates at $2 \times 10^{3}$ cells/well and incubated overnight. MTT solution ( $5 \mathrm{mg} / \mathrm{ml}$ in PBS, $20 \mu \mathrm{l} /$ well) was added to the cells to produce formazan crystals. MTT solution was substituted by $150 \mu \mathrm{l}$ DMSO $4 \mathrm{~h}$ later to solubilize the formazan crystal. The optical absorbance was determined at
$490 \mathrm{~nm}$ using an iMark microplate reader (Bio-Rad, USA).

\section{Oligonucleotide Transfection}

MiR-335 mimics, negative control (NC), antagomir-335, antagomir-NC and Daam1 silencing oligonucleotides (siDaam1) (RiboBio, China) were transfected using Lipofectamine RNAiMAX (Invitrogen) according to manufacturer suggested procedures. Transfection efficiency was evaluated by Cy3-labeled oligonucleotides negative control (data not shown).

\section{Colony Formation Assay}

Colony formation was evaluated as previously described [21]. Twenty-four hours after transfection, 200 500 transfected cells were placed in a fresh six-well plate and maintained in DMEM containing 10\% FBS for 7 to 10 days. Colonies were fixed with methanol and stained with $0.1 \%$ crystal violet in 20\% methanol for $15 \mathrm{~min}$, and representative colonies were photographed.

\section{Cell Invasion Assay}

Cell culture chamber with $8 \mu \mathrm{m}$ pore size polycarbonate membrane filters (BD Biosciences, USA) were used for cell invasion assay. The filters were pre-coated with $50 \mu \mathrm{l}$ Matrigel $(1.25 \mathrm{mg} / \mathrm{ml})$. Cells transfected with respective RNAs were harvested and seeded $1 \times 10^{5}$ cells/well with $1 \%$ FBS medium in upper chambers which were soaked in the bottom chambers filled with $0.6 \mathrm{ml}$ complete medium. At the same time, equal cells of the each group were plated to 96-well plates for cell number assay (MTT). The chamber was incubated at $37^{\circ} \mathrm{C}$ for $36 \mathrm{~h}$ and then the Matrigel was removed. The invaded cells were fixed with $4 \%$ paraform and stained with hematoxylin before photography and calculation. The invasiveness of cells was evaluated by the percentage-of-invasion (invaded cell number/total cell number $\times 100 \%$ ).

\section{Cell-Cycle Analysis}

Cells were collected by trypsinization, washed in PBS, and fixed in $70 \%$ ethanol for $30 \mathrm{~min}$ at $4^{\circ} \mathrm{C}$. After washing with PBS, cells were incubated with the DNA-binding dye propidium iodide $(50 \mu \mathrm{g} / \mathrm{ml})$ and RNase $(1.0 \mathrm{mg} / \mathrm{ml})$ for $30 \mathrm{~min}$ at $37^{\circ} \mathrm{C}$ in the dark. Finally, cells were washed and red fluorescence was analyzed by a FACSCalibur flow cytometer (BD, Germany) using a peak fluorescence gate to discriminate aggregates.

\section{Caspase 3/7 Activation Assay, Hoechst Staining, and TUNEL Assay}

For caspase $3 / 7$ activation assay, cells were seeded into 96-well plates at $2 \times 10^{5}$ cells per well and transfected with antagomir-335 or antagomir-NC at the indicated concentration for $72 \mathrm{~h}$. Meanwhile, cells with the same 
treatment of each group were plated to 96-well plates for cell number assay (MTT). Caspase activity was determined using Caspase-Glo 3/7 Assay (Promega, USA) according to the manufacturer's instructions, and evaluated as follows: caspase activity/cell number $\times 100 \%$.

For Hoechst 33258 staining, cells were fixed with $4 \%$ paraform for $10 \mathrm{~min}$, stained with Hoechst 33258 (5 ug/ml, Sigma) for $15 \mathrm{~min}$ in the dark, and observed by fluorescence microscopy (Olympus, USA) with a $340 \mathrm{~nm}$ excitation filter.

For TUNEL assay, apoptotic cells in $4 \mu \mathrm{m}$ sections of paraffin-embedded tumor samples or antagomir-335 treated cells were detected by In Situ Cell Death Detection Kit-TMR red (Roche, Germany) according to the manufacturers' instructions and the samples were analysed by fluorescence microscopy (Olympus) with a $540 \mathrm{~nm}$ excitation filter. The total number of apoptotic cells was quantified in 5 randomly selected microscopic fields.

\section{Western Blot Analysis}

Western blot was perform as described [22].The following antibodies were used: antibodies against DAAM1(1:500; Santa Cruz Biotechnology, USA), GFAP, phosphorylation (Ser 19) of MLC (1:1,000; Cell Signaling Technology, USA) and $\beta$-actin (1:2,000; New England Biolabs, USA).

\section{Luciferase Assay}

The potential binding sites of miR-335 within Daam1 3'UTR were obtained by TargetScan and PicTar. Synthetic oligos including predicted binding sites were annealed then cloned into Xho I/Not I site of psiCHECK-2 (Promega). C6 cells were transiently transfected with wide type (WT) or mutant (MUT) reporter vector and microRNA using Lipofectmine 2000 (Invitrogen) at the indicated concentrations. Luciferase activity was measured $48 \mathrm{~h}$ posttransfection using the Dual-Luciferase Reporter Assay System (Promega) followed the manual. Renilla luciferase activity was normalized to corresponding firefly luciferase activity and plotted as a percentage of the control.

\section{Real-Time PCR-Based Detection of MiR-335 and Rat Daam1-mRNA}

Total RNA was prepared using TRIZOL reagent (Invitrogen). Expression of mature miR-335 was determined by stem-loop primer SYBR Green quantitive real time-PCR (qRT-PCR) and normalized to U6. The stem-loop primer sequence for reverse transcription was as follows: 5'-CTC AAC TGG TGT CGT GGA GTC GGC AAT TCA GTT GAG ACA TTT TT-3'. Rat Daam1 mRNA expression was detected by qRT-PCR and normalized to 18SrRNA. The generated cDNA was amplified with primers for miR-335 (5'-ACA CTC CAG CTG GGT CAA GAG CAA TAA CGA AA-3' and 5'-CTC AAC TGG TGT CGT GGA-3') for rat Daam1 (5'-ACT ACT ACA CCA GCA CCA-3' and
5'-ACT CTC CTC ACT TCC ATG-3'). All qRT-PCR were performed in triplicates.

\section{In Vivo Assay}

For antagomir pretreated study, antagomir-335-and antagomir-NC-transfected C6 cells $\left(1 \times 10^{6}\right)$ were prepared in $100 \mu \mathrm{l}$ serum free DMEM medium and then s.c. injected into either side of the posterior flank of each female BALB/c athymic 4-week nude mouse. Tumor growth was monitored by caliper measurement every two days for 2 weeks. Tumor volume (V) was calculated as follows: $\mathrm{V}=$ $\mathrm{L} \times \mathrm{W}^{2} \times 0.5$; L, length; W, width. Tumor weight was detected at the end of the study.

For antagomir treatment, 4-week old athymic nude mice were s.c. injected with $1 \times 10^{5} \mathrm{C} 6$ cells; after approximately 10 days, when tumors became palpable, the tumorbearing nude mice were treated with antagomir-335. $50 \mu \mathrm{l}$ of antagomir-335 (diluted in PBS at $4 \mathrm{mg} / \mathrm{ml}$ ), or control antagomir-NC were injected intratumorally every two days for 2 weeks. Tumor growth was monitored every two days for 3 weeks. Tumor volume (V) and weight was calculated as described above.

\section{Confocal microscopy}

Cells were grown on glass coverslips to $30 \%$ confluence and transfected with RNAs for $36 \mathrm{~h}$. The mediums were removed and cells were rinsed with PBS twice. Cells were fixed with $4 \%$ paraformaldehyde for $30 \mathrm{~min}$, washed three times with PBS and then penetrated and blocked with PBS containing $0.2 \%$ Triton X-100 and $5 \%$ bovine serum albumin for $1 \mathrm{~h}$. The blocking buffer was removed and incubated with phallotoxins (5 Units/ml, Molecular probe, USA,) over night at $4^{\circ} \mathrm{C}$. Cells were washed three times with penetrating buffer. Images were photographed with a Zeiss LSM 510 Confocal Microscope (Carl Zeiss Microimaging, Thornwood, NY).

\section{Immunohistochemistry}

Immunohistochemistry staining of $4 \mu \mathrm{m}$ sections of paraffin-embedded samples were performed as described [23]. Sections were stained with primary antibody DAAM1 (1:50) overnight at $4^{\circ} \mathrm{C}$, bio-anti mouse IgG for $1 \mathrm{~h}$ and then incubated with avidin biotin-peroxidase complex diluted in $\mathrm{NaCl} / \mathrm{Pi}$.

\section{Statistical Analysis}

Data are presented as mean \pm SD of three separated experiments if not noticed. A difference with a $P$ value $<$ 0.05 by ANOVA was considered statistically significant.

\section{Results}

MiR-335 is highly expressed in malignant astrocytoma

We found 8 expressed miRNAs (miR-593, miR-129-1, miR-335, miR-182, miR-96, miR-183, miR-29a, miR-29b-1) 
resided on chromosome $7 \mathrm{q} 32$, a hot spot that frequently gained in astrocytoma(Figure 1A). Among these miRNAs, miR-335 expression between C6 astrocytoma cells and rat normal astrocytes was analyzed by qRT-PCR. Interestingly, the expression of miR-335 was markedly upregulated in C6 cells (Figure 1B). To further confirm and extend this finding, we investigated the expression of miR-335 in a subset of human astrocytoma tissues. Consistently, we also observed a significant higher level of miR-335 in astrocytoma patient samples with respect to their paracancerous counterparts (Figure 1B). These results raise a possibility that miR-335 might be an oncomiRNA in malignant

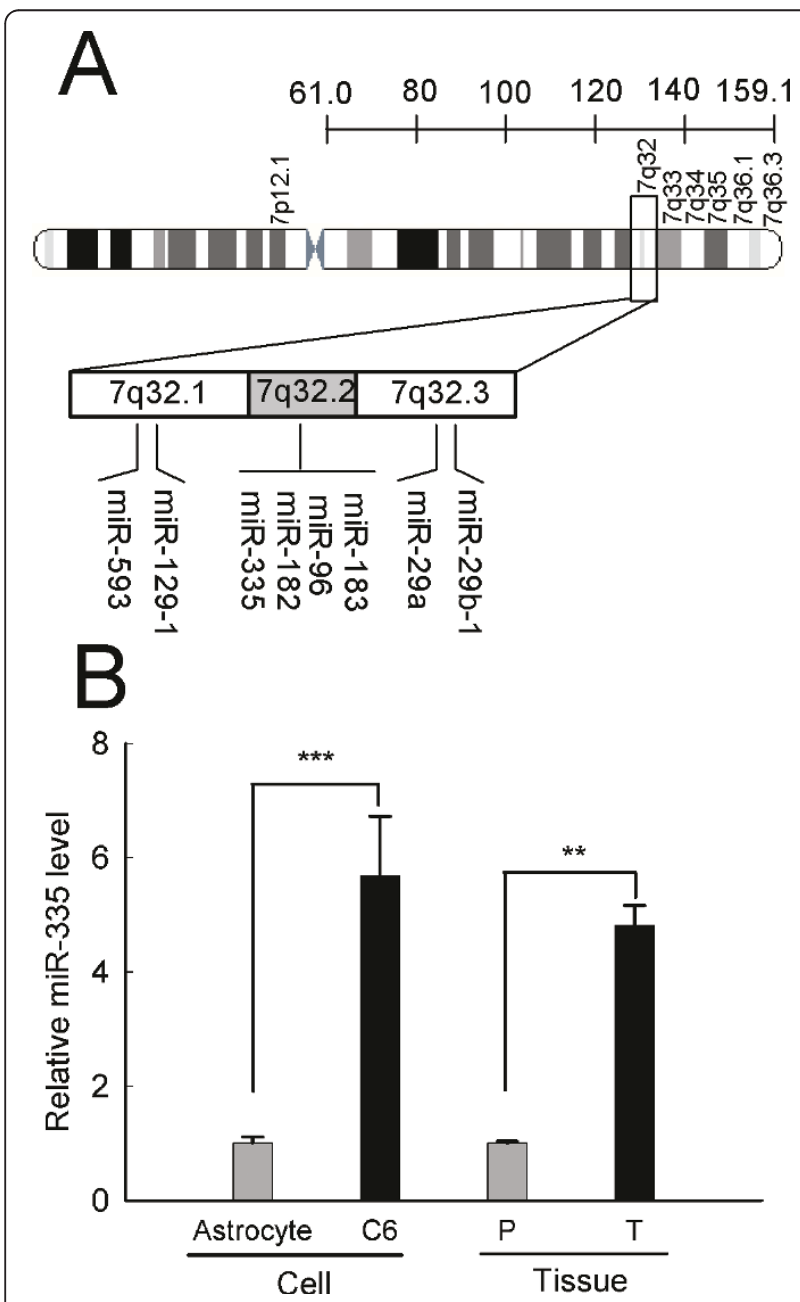

Figure 1 MiR-335 is highly expressed in astrocytoma. (A) A schematic showing miRNAs located on chromosome 7q32 in astrocytoma. (B) Data shown are expression level of miR-335 in C6 astrocytoma cells and patient astrocytoma tissues by real-time quantitative RT-PCR, comparing with their relative normal counterparts. P, adjacent paracancerous tissues; T, patient astrocytoma tissues. RNA input was normalized by U6 snRNA. Data represent the means \pm SD of three independent experiments. Statistical differences compared with the controls are given as **, $P<0.01 ;{ }^{* *}, P<0.001$. astrocytoma and might well have a role in malignant astrocytoma pathogenesis.

\section{MiR-335 positively regulates viability and invasion of C6 cells in vitro}

To elucidate the potential role of miR-335 in astrocytoma pathogenesis, we first performed in vitro gain-of-function analyses by introducing miR-335 mimics into C6 cells. Ectogenic miR-335 dramatically enhanced cell viability in dose-and time-dependent manners (Figure 2A, B) and significantly promoted colony formation (Figure $2 \mathrm{C}$ uppanel, 2D). Moreover, miR-335 overexpression could also result in marked increase of cell invasiveness (Figure $2 \mathrm{E}$ up-panel, 2F). Notably, miR-335 overexpression failed to transform but strongly enhanced the oncogenic properties such as the invasiveness and viability of primary cultured normal astrocytes (Additional file 2 Figure S1).

To determine the consequence of miR-335 inhibition in astrocytoma cells, we delivered an antagonist specific for miR-335 (antagomir-335) into C6 cells. Effective miR-335 inhibition strongly suppressed cell growth (Figure $2 \mathrm{G}, \mathrm{H}$ ), colony formation (Figure 2C down-panel, 2D) and cell invasion (Figure 2E down-panel, 2F). Importantly, knockdown of miR-335 exhibited little sign of viability inhibition on normal astrocytes (Figure 2I), suggesting a specific anti-tumor effect of miR-335 inhibition. Heretofore, all the results authentically indicate an oncomiRNA character of miR-335 as promoting oncogenic phenotypes in astrocytoma.

\section{MiR-335 abrogation induces apoptosis in C6 cells}

The growth-inhibitory effect of antagomir-335 led us to further investigate whether miR-335 silencing may inhibit cell proliferation and/or induce apoptosis. By flow cytometry analysis, we observed no change on cell cycle distribution (Figure 3A). Nevertheless, apoptotic cells with characteristic morphologic alterations such as cell shrinkage were observed (Figure 3B). Specifically, Hoechst staining and quantification of the number of cells with condensed and fragmented nuclei indicated that antagomir-335 treated cells underwent apoptosis (Figure 3C, D). In line with this observation, TUNEL assay also showed an increased apoptosis in antagomir-335 treated C6 cells (Figure 3E, F).Furthermore, caspase 3/7 activity was markedly enhanced in a dose-dependent manner after $72 \mathrm{~h}$ antagomir-335 tranfection, confirming miR-335 abrogation-induced apoptosis (Figure $3 \mathrm{G}$ ). These results suggest that antagomir-335 induced growth arrest was, at least in part, caused by apoptosis.

\section{Daam 1 is a direct target of miR-335}

To identify specific gene targets of miR-335 by which it might promote oncogenic behaviors, we searched diverse target prediction databases (TargetScan, Pictar) for 

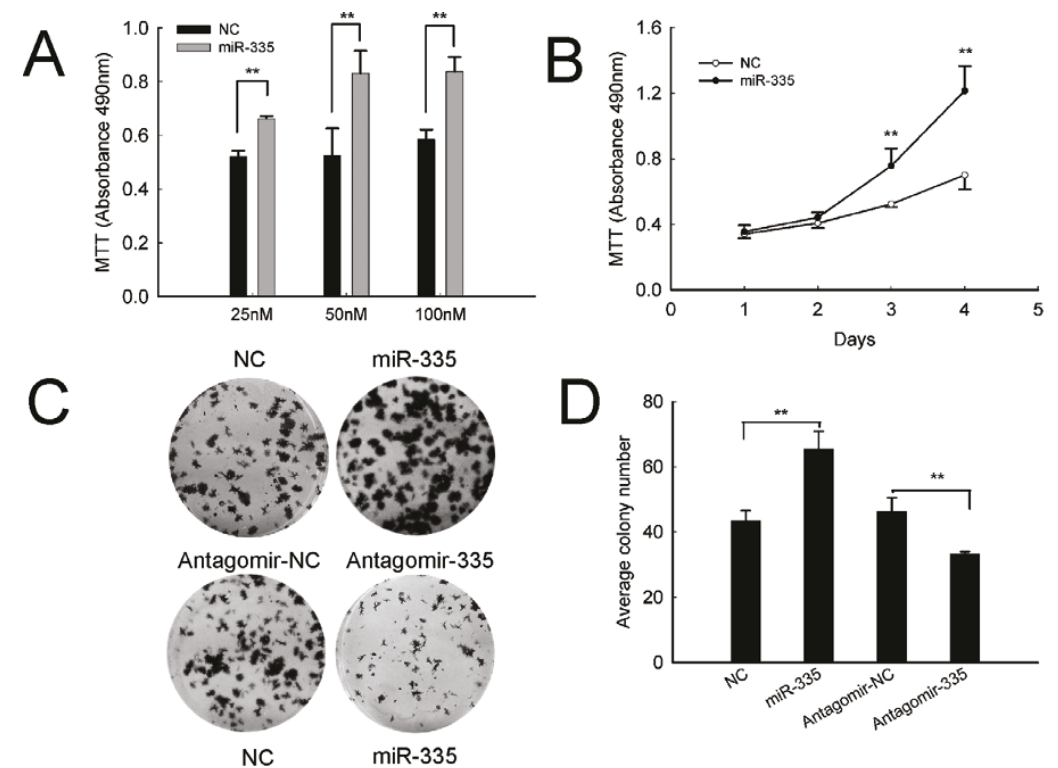

D
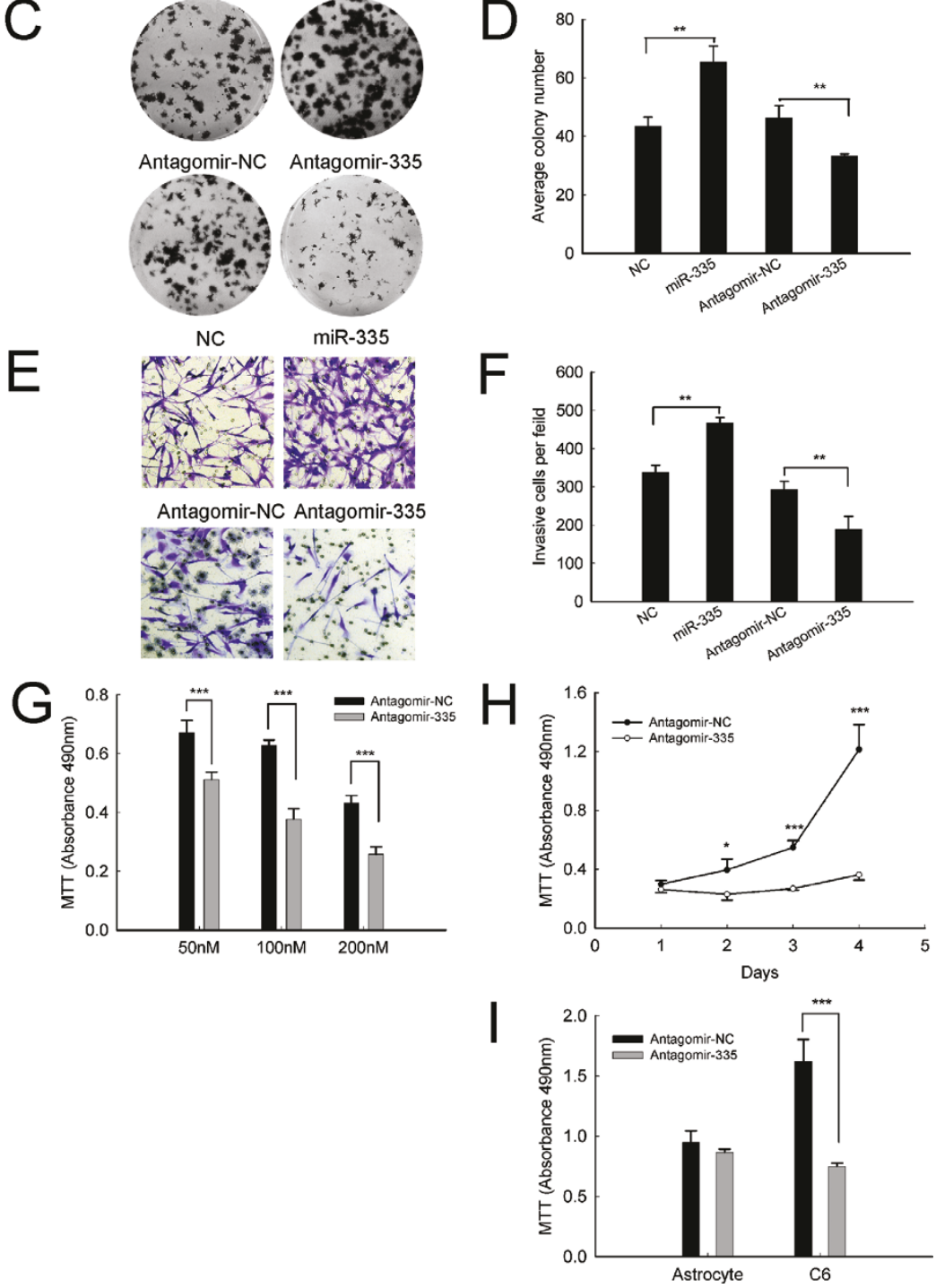

Figure 2 Effects of miR-335 on viability and invasion in C6 astrocytoma cells. (A) Dose-dependent effect of miR-335 mimics on cell viability. C6 cells were transfected with miR-335 mimics or negative control mimics (NC) for $72 \mathrm{~h}$ at the indicated concentrations. (B) Timedependent effect of miR-335 mimics on cell viability. C6 cells were transfected with $50 \mathrm{nM}$ miR-335 mimics for the indicated times. (C, D) Colony formation was observed at the presence of miR-335 mimics (C up-panel) or antagomir-335(C down-panel). (E, F) Cell invasiveness was detected by transwell invasion assay. C6 cells were transfected with $50 \mathrm{nM}$ miR-335 mimics (E up-panel) or $100 \mathrm{nM}$ antagomir-335 (E down-panel) or their counterpart negative controls. Graph is the representative of three independent experiments. (G) Dose-dependent effect of antagomir-335 on cell viability. C6 cells were transfected with antagomir-335 or antagomir-NC for $72 \mathrm{~h}$ at the indicated concentrations. (H) Time-dependent effect of antagomir-335 on cell viability. C6 cells were transfected with $100 \mathrm{nM}$ antagomir-335 for the indicated times. (I) Cell viability was measured with MTT assay. Rat normal astrocytes and C6 astrocytoma cells were transfected with $100 \mathrm{nM}$ antagomir-335 or antagomir-NC for $72 \mathrm{~h}$. Data represent the means $\pm S D$. Statistical differences compared with the controls are given as ${ }^{*}, P<0.05 ;{ }^{*}, P<0.01 ;{ }^{* *}, P<0.001$. Original magnification in (E), $200 \times$ 


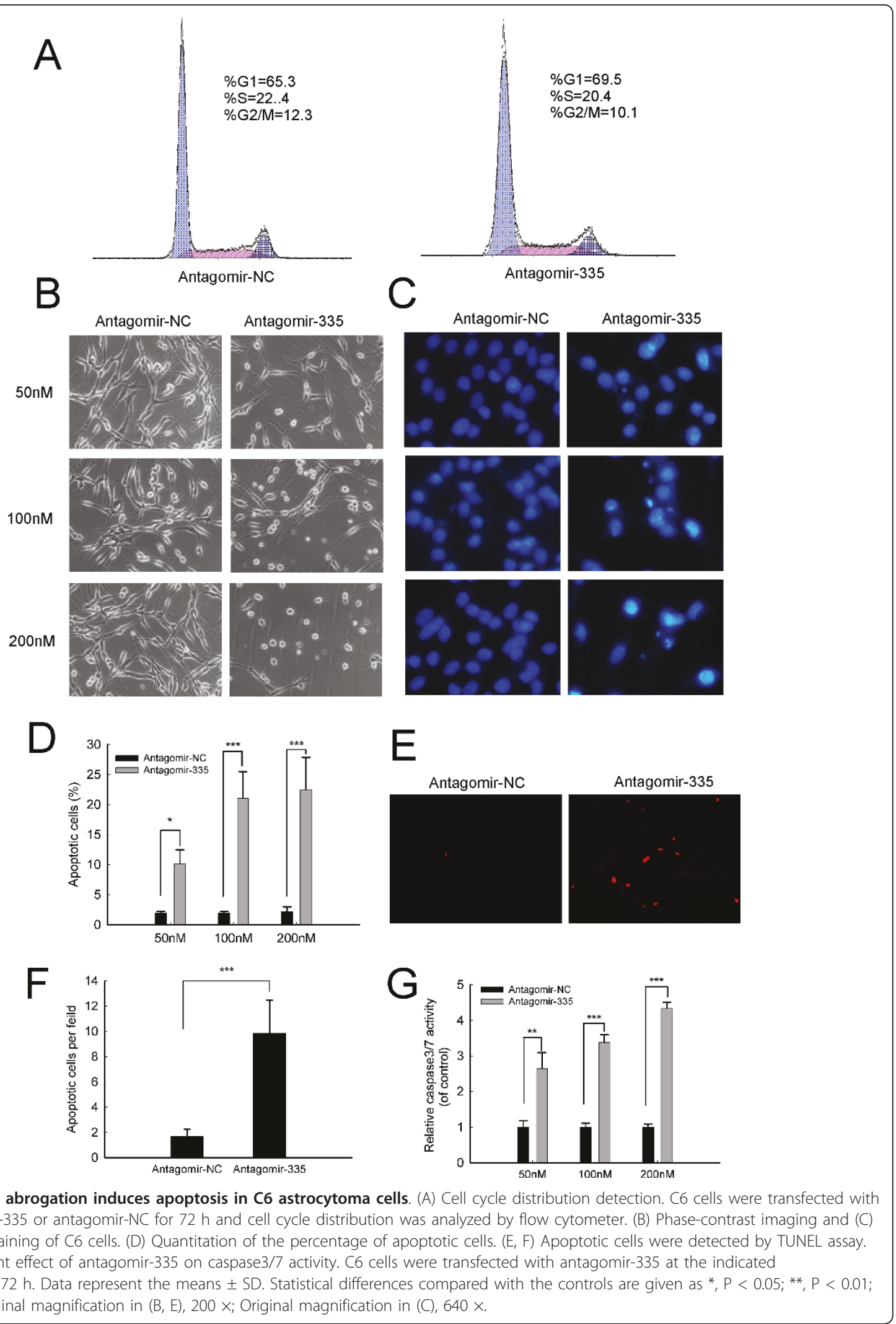


theoretical target genes whose downregulation could mediate the observed effects of miR-335. Among all the putative targets, Daam1, Rasa1 and Map2 which we chose for our further study were known to play important roles in cell motility or proliferation $[24,25]$. The predicted miR335 binding sites were shown (Figure 4A, Additional file 2 Figure S2). Interestingly, after introducing miR-335 into C6 cells and normal astrocytes, a dramatic downregulation of DAAM1 protein in a dose-dependent manner was concurrent with an unaltered Daam1 mRNA (Figure 4B, C, Additional file 2 Figure S3), indicating a posttranscriptional modulation of miR-335 on Daam1. In parallel experiments, no obvious changes of RASA1, and MAP2 protein levels could be detected (Additional file 2 Figure S4). Then, a consistent reduction of luciferase activity of the reporter that contained wild-type 3'-UTR of Daam1 mRNA was observed in the condition of extra miR-335 (Figure 4D), while the luciferase activity of mutant reporter was almost unaffected. In contrast, the addition of antagomir-335 in C6 cells increased luciferase activity (Figure 4E), associated with the upregulation of DAAM1 protein (Figure 4F uppanel). Importantly, the phosphorylation of MLC (myosin light chain) which is a downstream factor of DAAM1 and the direct trigger of apoptosis was strongly induced after antagomir-335 transfection (Figure 4F down-panel).

To further discern the regulatory role of endogenous miR-335 in DAAM1 protein expression, we analyzed the protein level of DAAM1 in C6 cells and normal astrocytes in which miR-335 level had been detected by qRT-PCR (Figure 1B). As expected, we observed a sharp reduction of DAAM1 protein in miR-335-overexpressed C6 cells (Figure 4G left-panel, 2H). Here, GFAP expression was used as a biomarker of primary cultured normal astrocytes. Importantly, this reciprocal expression pattern was further confirmed in a set of resected human astrocytoma tissue samples. As Figure 4G right-panel, $2 \mathrm{H}$ shown, DAAM1 was highly expressed in all of the respective adjacent paracancerous fields, but barely detectable in human astrocytoma tissues, although the degree of low-expression varied from one sample to another. These data indicate that miR-335 may inhibit the expression of Daam 1 at posttranscriptional level by directly targeting the 3'-UTR of Daam1 mRNA.

\section{Knockdown of Daam1 mimics the oncogenic effects of miR-335 in C6 cells}

To determine whether Daam1 is a functional target of miR-335 in malignant astrocytoma cells, we investigated whether reduction of Daam1 expression could mimic the growth and invasion-promoting effects of miR-335. As Figure 5A shown, knockdown of Daam1 (siDaam1) in C6 cells for $48 \mathrm{~h}$ resulted in a major reduction in DAAM1 protein, the repression effect was also observed by miR335 transfection. Effective Daam1 silencing could dramatically stimulate viability and colony formation of C6 cells, which were similar to that of miR-335 transfection (Figure 5B,C). Moreover, both miR-335 and siDaam 1 transfected cells showed a dramatic cytoskeleton rearrangement characterized by a loss of actin stress fibers and induction of actin-positive membrane ruffles (Figure 5D). Accordingly, an enhanced invasiveness was further observed both in miR-335 and siDaam1 treated cells (Figure 5E). These findings suggest that Daam 1 repression may contribute to the miR-335-induced oncogenic features.

\section{Knockdown of Daam1 reverses the anti-tumor effects of antagomir-335 in $\mathrm{C} 6$ cells}

We further examined whether Daam1 abrogation counteracts the anti-tumor effects of antagomir-335. As Figure 6A shown, siDaam 1 effectively abolished the upregulation of DAAM1 induced by antagomir-335. Interestingly, the resulting Daam1 knockdown obviously rescued the antagomir-335-induced growth arrest, repression of colony formation and invasion (Figure 6B, C, D). Furthermore, siDaam 1 transfectants also significantly decreased the caspase3/7 activity induced by antagomir-335(Figure 6E). Taken together, all these data suggest that Daam 1 is potentially involved in miR-335-regulated growth and invasion.

\section{MiR-335 inhibition suppresses tumor growth in vivo}

Based on the in vitro studies, we hypothesized that abolition of miR-335 expression might have anti-tumor effects in vivo. To address this critical question, we used two in vivo xenograft models. In pretreated model, as shown in Figure 7A-C, pre-transfection of antagomir-335 into C6 cells led to a significant reduction in both tumor volume (Figure 7A, B) and weight (Figure 7C) compared with antagomir-NC transfectant. Furthermore, to determine whether inhibition of miR-335 may have therapeutic effects, C6 cells were injected into nude mice, and tumors thereby generated were treated with antagomir-335 or antagomir-NC for two weeks(Figure 7D). In line with the pretreated model, intratumorally injection of antagomir-335 dramatically inhibited tumor growth and weight (Figure 7E, F). Intriguingly, the ratio of the anterior flank metastasis was as high as $40 \%$ in antagomir-NC group; however, no metastasis was observed in antagomir-335 group (Additional file 2 Figure S5). Consistently, immunohistochemistry showed a marked increase of DAAM1 protein level in antagomir-335 treated group (Figure 7G). In addition, TUNEL assay showed an increased apoptosis in tumors administrated with antagomir-335, as compared to the control group (Figure $7 \mathrm{H}$ ). All these results suggest that miR-335 may confer a survival advantage to astrocytoma cells and that it might be a novel potential therapeutic target for malignant astrocytoma therapy. 


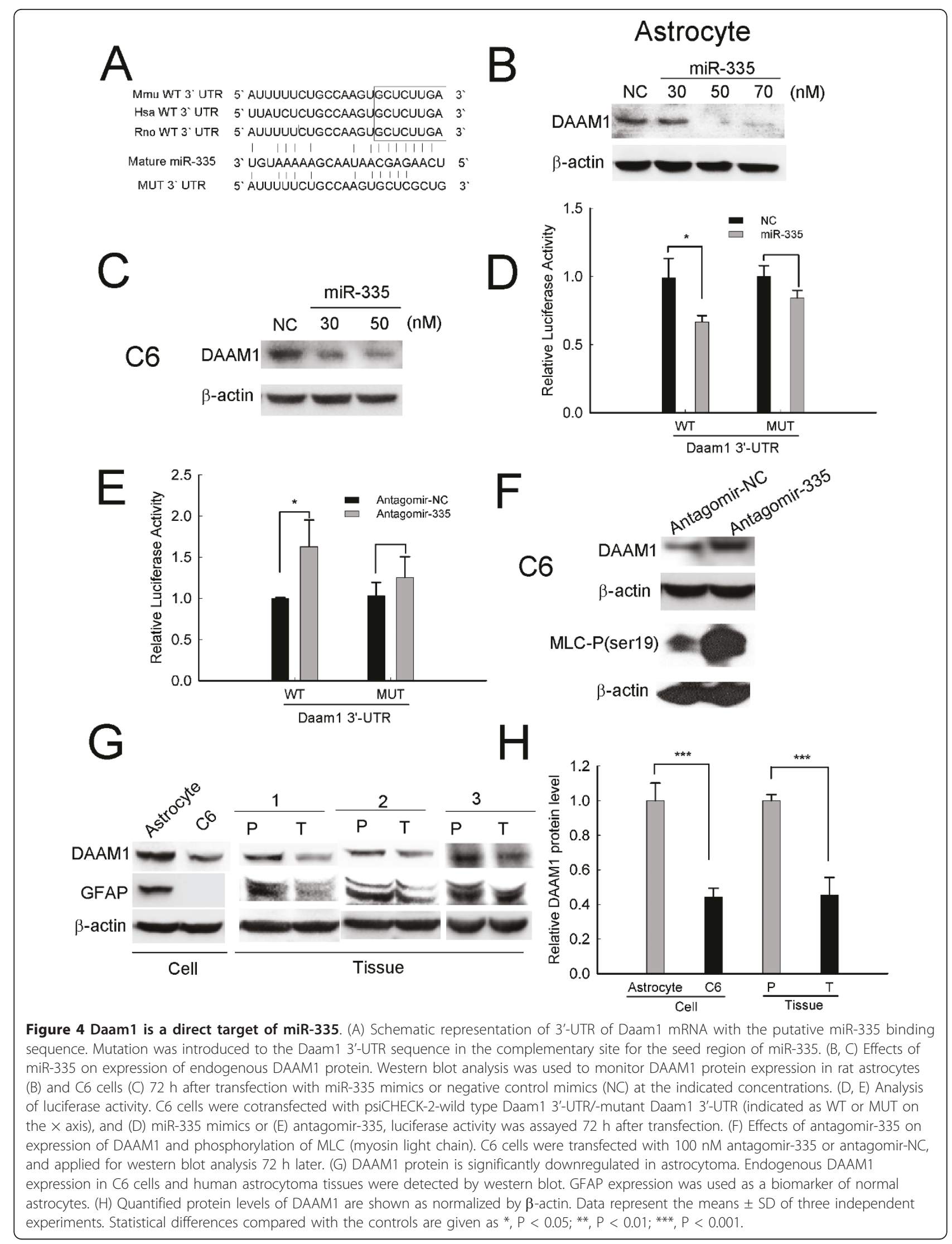




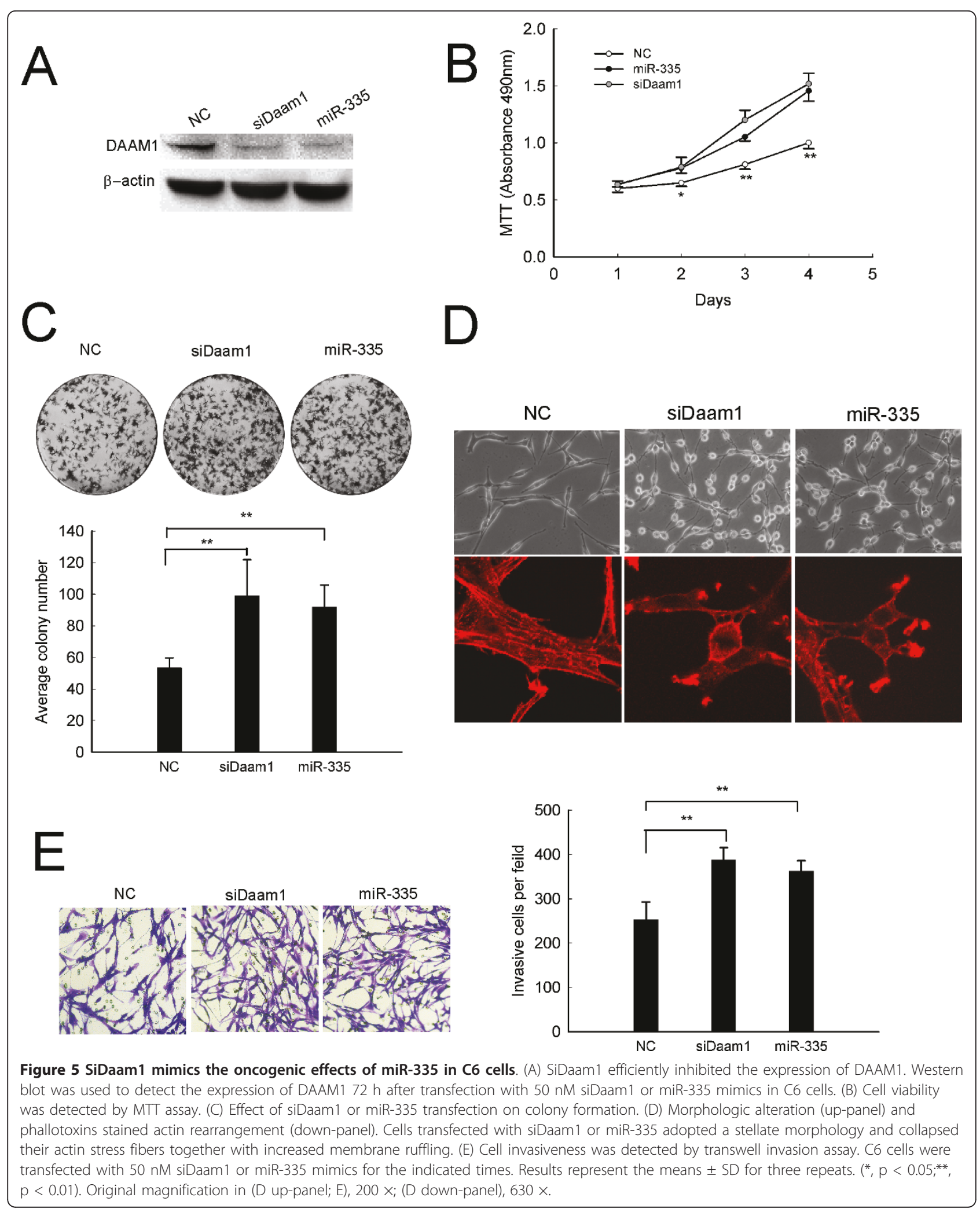




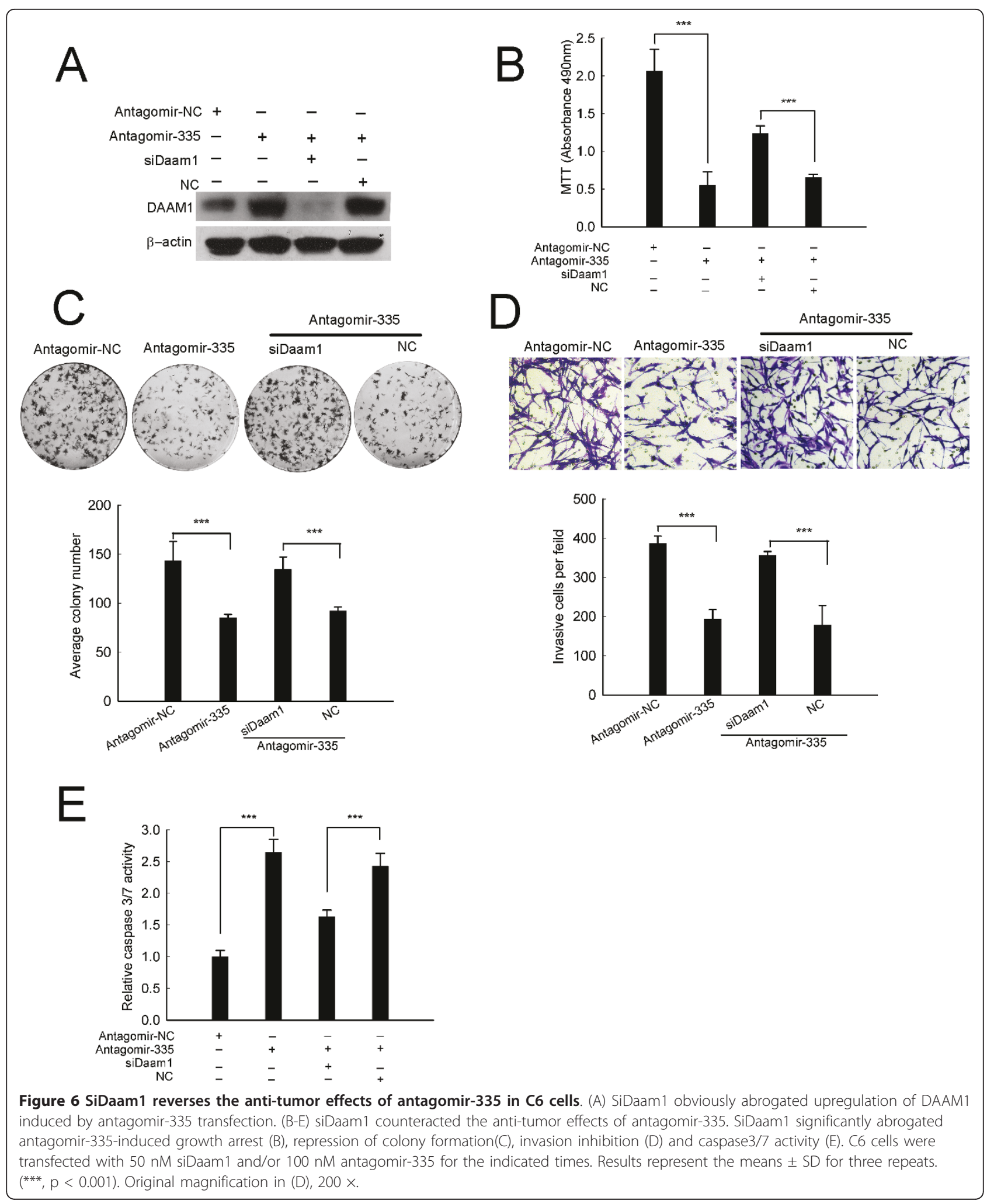




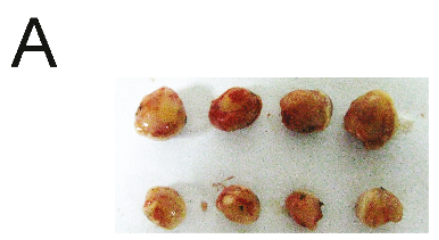

B

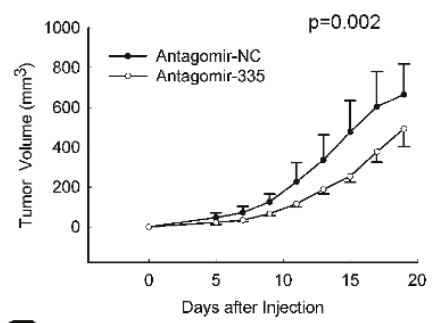

C

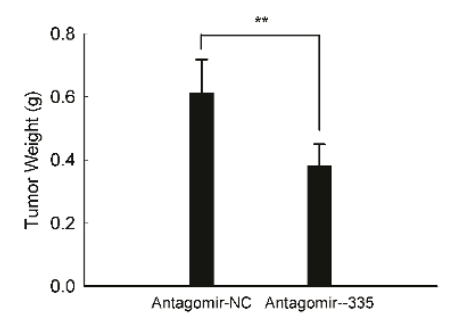

G
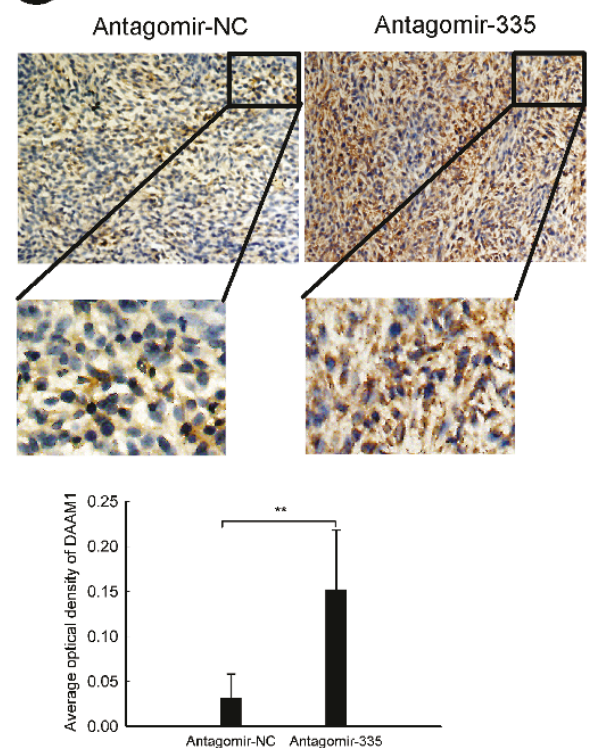

D
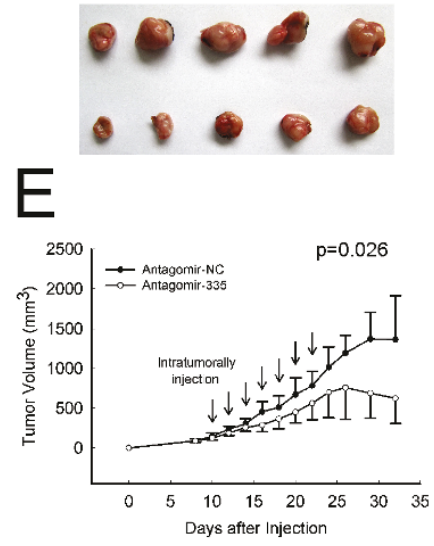

$\mathrm{F}$

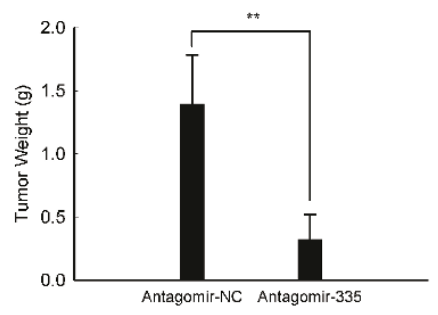

$\mathrm{H}$
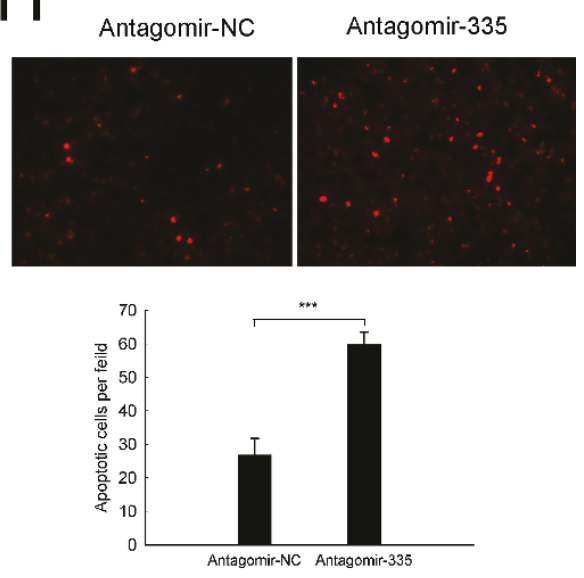

Figure 7 MiR-335 inhibition suppresses tumor growth in vivo. (A-C) Pretreated effect of antagomir-335 on tumor formation in nude mouse xenograft model. (A)Antagomir-NC-transfected and antagomir-335-transfected C6 cells were s.c. injected into the left (up-panel) and right (down-panel) flanks of nude mice, respectively $(n=8)$. (B) Tumor volume was monitored during the time course of 19 days. (C) Tumor weight was detected at the end of the study. (D-H) Therapeutic effect of antagomir-335 on tumor growth in nude mouse xenograft model. (D) Tumors generated by C6 cells injection in nude mice were intratumorally injected with antagomir-NC (up-panel) and antagomir-335 (down-panel) for 2 weeks, respectively $(n=5)$. (E) Tumor volume was monitored during the time course of 4 weeks. (F) Tumor weight was detected at the end of the study. (G) DAAM1 expression was detected by immunohistochemistry. (H) Apoptotic cells were detected by TUNEL assay. Data represent the means $\pm S D$. Statistical differences compared with the controls are given as ${ }^{* *}, P<0.01$; ${ }^{* *}, P<0.001$. Original magnification in $(G$ up-panel), $320 \times$; Original magnification in $(H), 400 \times$. 
Both miR-335 and siDAAM1 promote growth and invasion of human U87-MG astrocytoma cells

To test whether our findings extend to human astrocytoma cells, we first compared miR-335 expression between human astrocytoma U87-MG cells and human normal astrocyte HEB cells. Consistent with the C6 cells, the expression of miR-335 was markedly upregulated in U87-MG astrocytoma cells (Figure 8A). Furthermore, ectogenic expression of miR-335 significantly promoted viability of U87-MG cells in a time-dependent manner (Figure 8B). And an enhanced colony formation was further observed (Figure 8C). Importantly, this colony-promoting effect was also detected by effective DAAM1 abrogation (Figure 8C, D). Moreover, cells transfected with miR-335 or siDAAM1 showed a loss of actin stress fibers, adopting more of a stellate morphology with an increase of actin-rich cell processes and membrane ruffles (Figure $8 \mathrm{E}$ ). We also observed that both miR-335 and siDAAM1 efficiently accelerated the invasiveness of U87-MG cells in vitro (Figure 8F). In addition, the expression of DAAM1 was substantially downregulated after miR-335 transfection (Figure 8G left-panel). Moreover, the reciprocal expression pattern between endogenous miR-335 and DAAM1 was further confirmed in HEB and U87-MG cells (Figure 8G rightpanel). All of the above findings together with those observed in C6 cells suggested that miR-335 might act as an oncomiRNA both in rat and human malignant astrocytoma pathgenesis.

\section{MiR-335 inhibition induces apoptosis and suppresses invasion in human U87-MG astrocytoma cells}

The anti-tumor effects of miR-335 abrogation were further investigated in U87-MG cells. As Figure 9A, B, C, shown, antagomir-335 strongly inhibited viability, colony formation and invasion of U87-MG cells. Moreover, after exposure to antagomir-335, the U87-MG cells displayed all of the apoptotic morphological alterations such as shrinkage of the cell, condensation of chromatin, and disintegration of the cell into small fragments (Figure 9D, E). Consistently, TUNEL assay showed an increased apoptosis in antagomir-335 transfected U87-MG cells (Figure 9F). We also observed caspase 3/7 activity was markedly enhanced after $72 \mathrm{~h}$ antagomir-335 tranfection, confirming miR-335 abrogation could induce caspase-mediated apoptosis in human astrocytoma cells (Figure 9G). In addition, the expression of DAAM1 was substantially upregulated after antagomir-335 transfection (Figure 9H left-panel). Moreover, the phosporylation of MLC (myosin light chain) was also highly induced (Figure $9 \mathrm{H}$ right-panel). All of the above findings seem to demonstrate that antagomir-335 is able to induce apoptosis and suppress invasion in both rat C6 and human U87-MG astrocytoma cells, which indicates the anti-tumor effects of miR-335 abrogation are evolutionarily conserved from rat to human in malignant astrocytoma.

\section{Discussion}

Malignant astrocytomas are one of the leading causes of cancer deaths in central nervous system characterized by unlimited proliferation and progressive local invasion $[1,26]$. Unfortunately, the underlying molecular mechanisms resulting in astrocytomagenesis and local invasion remain obscure so far and stand for the major obstruction in finding novel therapeutic strategies [27]. In this study, we found that miR-335 targeted a potential tumor suppressor Daam1, which promoted several oncogenic features such as growth and invasion in astrocytoma cells. Furthermore, miR-335 inhibition could effectively suppress growth and induce apoptosis of astrocytoma cells both in vitro and in vivo. Importantly, the anti-tumor effects of miR-335 abrogation also extended to human astrocytoma cells. Thus, miR-335 might act as an evolutionarily conserved oncomiRNA in astrocytoma pathogenesis and represent a potential therapeutic target for this highly aggressive and, as yet, therapy-refractory tumor.

Genetic aberration patterns specific for different grades of astrocytoma have been defined previously [12]. Gain of chromosome 7 with a hot spot at 7q32 appears to be the most prominent aberration and an early event in tumorigenesis of astrocytoma, whereas in glioblastoma multiforme, gain of $7 \mathrm{p} 12$ seems to be the most frequently affected band on chromosome 7 [12]. We found 8 expressed miRNAs (miR-593, miR-129-1, miR335, miR-182, miR-96, miR-183, miR-29a, miR-29b-1) reside on $7 q 32$, some of which have been investigated, either as oncogenes or tumor suppressor genes [13-15]. It is becoming increasingly clear that chromosomal abnormalities and/or epigenetic events contribute to miRNA deregulation [28]. Our data showed that the intronic miR-335, flanked by MEST imprinting gene in the 7 q32.2 region, was highly expressed in astrocytoma cell lines and tissues. Intriguingly, genomic copy number analysis revealed statistically significant amplification of miR-335 locus in U87-MG cell line and II-III grade malignant astrocytoma tissues (Additional file 2 Figure S6). Moreover, we also determined the miR-335 expression level in glioblastoma multiforme T98G cell line, and found that it was slightly upregulated compared to HEB (Additional file 2 Figure S7). Loss of function study also showed that inhibition of miR-335 in T98G cells had little effect on their growth (Additional file 2 Figure S8). Therefore, we hypothesize that the observed increased expression of miR-335 may partially result from 7q32.2 regional amplification, and miR-335 may act as an early promoter and a biomarker during tumorigenesis of astrocytoma. 


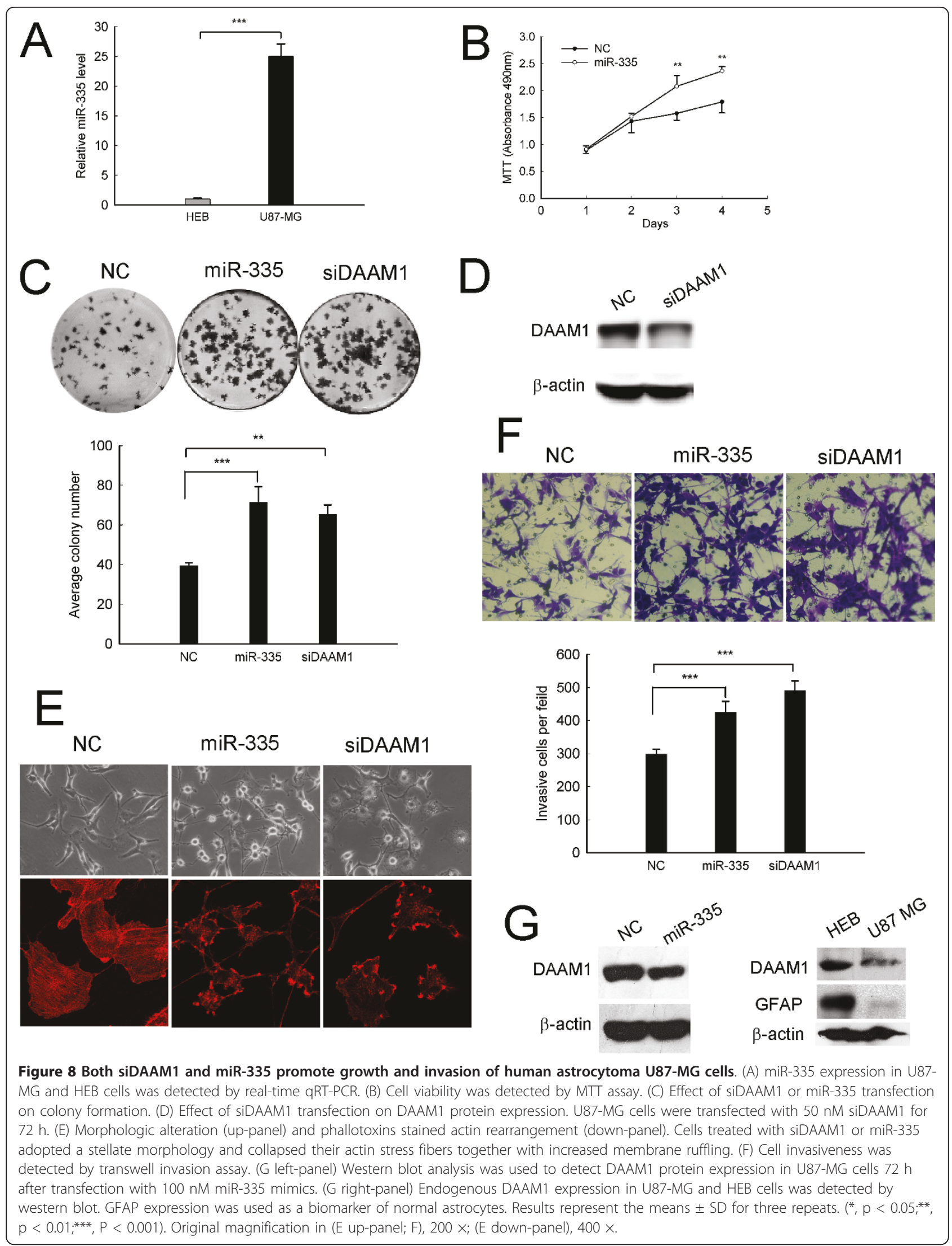




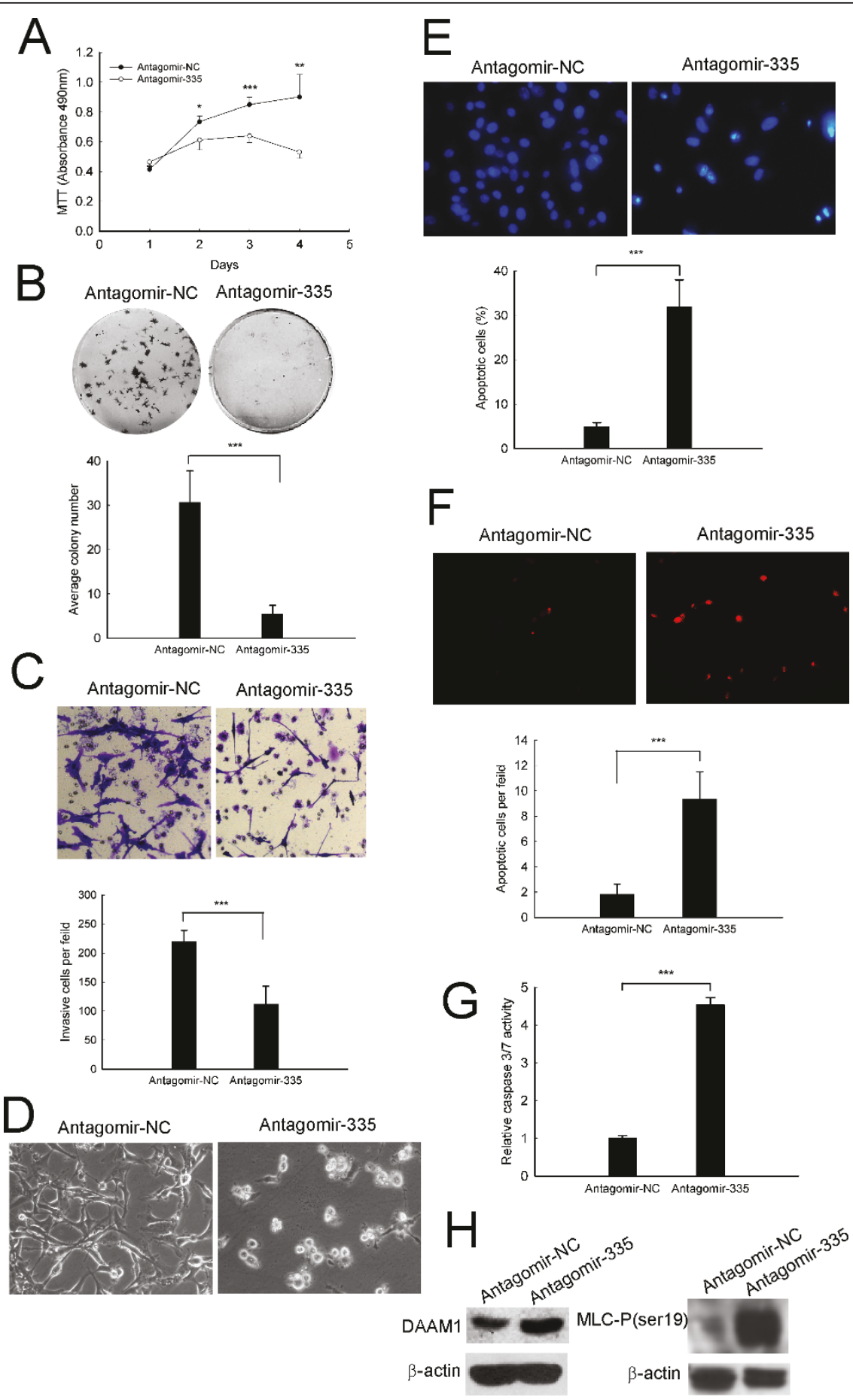

Figure 9 MiR-335 inhibition induces apoptosis and suppresses invasion of human astrocytoma U87-MG cells. (A) Time-dependent effect of antagomir-335 on cell viability. U87-MG cells were transfected with $100 \mathrm{nM}$ antagomir-335 for the indicated times. (B) Effect of antagomir-335 transfection on colony formation. (C) Cell invasiveness was detected by transwell invasion assay. U87-MG cells were transfected with $100 \mathrm{nM}$ antagomir-335 or antagomir-NC. Graph is the representative of three independent experiments. (D) Phase-contrast imaging and (E) Hoechest 33258 staining of U87-MG cells. (F) Apoptotic cells were detected by TUNEL assay. (G) Effect of antagomir-335 on caspase3/7 activity. U87-MG cells were transfected with $100 \mathrm{nM}$ antagomir-335 or antagomir-NC for $72 \mathrm{~h}$. (H) Effect of antagomir-335 on expression of DAAM1 (left-panel) and phosphorylation of MLC (right-panel) in U87-MG cells. Cells were transfected with $100 \mathrm{nM}$ antagomir-335 or antagomir-NC for 48 h. Data represent the means \pm SD. Statistical differences compared with the controls are given as ${ }^{*}, P<0.05 ; * *, P<0.01$; ***, $P<0.001$. Original magnification in (C, D, F), $200 \times$; Original magnification in (E), $400 \times$. 
To date, a panel of miRNA mutations or deletions have been reported, either tumor suppressors or oncogenes in multiple human cancers [5], including malignant astrocytomas [29]. Even more, impairment of microRNA regulatory network is considered as one of the key mechanisms in astrocytoma pathogenesis [30]. With regard to miR-335, it is normally expressed in a variety of human tissues and deregulated in several types of tumors [31-34], suggesting complex biological roles of this miRNA during tumorigenesis. Of particular interest, miR-335 was recently reported to suppress metastasis of human breast cancer via targeting of $\mathrm{SO} \times$ 4 and tenascin $C$, however, without affecting its proliferation [17]. This finding is apparently in contradiction with the function of miR-335 as an invasion promoter in malignant astrocytomas. Due to the fact that one miRNA can regulate more than one target gene, it is possible to speculate the selection of genes that would make major contributions to the phenotypes induced by the miRNA may depend on the cellular microenvironment. Therefore, we propose that the downregulation of DAAM1 induced by miR-335 may play a predominant role in mediating the pro-invasion effect of miR-335 in astrocytoma cells. Furthermore, it is also demonstrated that miR-335 regulates $\mathrm{Rb} 1$ and controls cell proliferation in a p53-dependent manner [18]. MiR-335 drives hyperproliferation in the absence of p53 and induces apoptosis and/or cell cycle arrest in the presence of wide-type p53 [18]. In our study, we showed that miR335 strongly promoted growth of C6 and U87-MG astrocytoma cells. However, it is well established that both C6 and U87-MG cells express wild type (wt)-p53 $[35,36]$. Moreover, we further detected the effect of miR-335 on Rb1 expression in astrocytoma cells. Surprisingly, transient transfection of C6 and U87-MG cells with miR-335 efficiently increased the Rb1 protein levels, as detected by Western blotting (Additional file 2 Figure S9). This discrepancy is likely due to the difference in cell context, and suggests that altered expression of this miRNA may have diverse effects in tumor cells. In fact, the interaction between miRNA and its target mRNA can be controlled by many factors. For example, recent studies have shown that there are AU-rich elements (AREs) resided in the vicinity of the microRNA target sites (seed sequence), and both AREs and seed sequence are highly conserved throughout evolution in mRNA 3'UTRs [37]. Intriguingly, two RNA binding proteins HuR and Dnd1 have been identified to counteract the function of miRNAs by binding AREs and blocking miRNAs from associating with their target sites [38,39]. Even more, both miR-369-3 and let-7 have been shown to activate target gene expression on cell cycle arrest by recruiting specific proteins to AREs [37]. Thus, it is reasonable to assume that astrocytoma cell-specific factors bind and counteract miR-335 function in these cells. Further experiments to clarify this discrepancy would be of great interest.

Dishevelled-associated activator of morphogenesis 1 (Daam1), a member of the formin protein family acting downstream of WNT signaling, plays an important role in regulating the actin cytoskeleton via mediation of linear actin assembly [40]. Previous functional studies of Daam1 suggest its essential roles in promoting proper cell polarization, migration, proliferation and tissue morphogenesis during embryonic development [41]. Inhibition of Daam1 results in an increase in cell migration of parietal endoderm [42] while activation of Daam1 suppresses endothelial cell proliferation, migration and angiogenesis [43]. It is also demonstrated that stably overexpressing Daam1 enhances myosin IIB stress fiber network which opposes cell migration [41]. Additionally, Daam1 has been linked to the control of cell behaviors by regulating downstream Rho/ROCK [42]. It is well established that inhibition of ROCK can promote motility of astrocytoma cells via actin rearrangement [44]. In line with these observations, our data showed that both miR-335 and knockdown of Daam1 (siDaam1) efficiently promoted invasion of C6 and U87MG astrosytoma cells, and an alteration of cell morphology as well as a loss of actin stress fibers together with induction of actin-positive membrane ruffles were also observed, indicating that the actin rearrangement may contribute to the pro-invasive effect of miR-335 in astrocytoma cells. Furthermore, ROCK is recognized as a major regulator of the morphological events that occur during the execution phase of apoptosis, including cell contraction, dynamic membrane blebbing, nuclear disintegration, and fragmentation of apoptotic cells into apoptotic bodies. It is reported that activation or overexpression of ROCK increases MLC (myosin light chain) phosphorylation and subsequently results in actomyosin contractility, membrane blebbing and apoptosis $[45,46]$. In our study, we found that antagomir-335 dramatically upregulated DAAM1 protein, meanwhile, the phosphorylation of MLC was also extremely stimulated both in C6 and U87-MG cells. These results suggest that antagomir-335 induced apoptosis may partially through the increase of DAAM1 which, in turn enhances MLC phosphorylation. In addition, it is noteworthy that siDaam1 was able to mimic the oncogenic behaviors of miR-335; however, it could only counteract partially the anti-tumor effects of antagomir335 . Therefore, it is likely that miR-335 has effects independent of DAAM1. Alternatively, it would be reasonable that the downregulation of DAAM1 could simply cooperate with the concomitant attenuation of other miR-335 targets.

Besides in vitro study, we also found that antagomir-335 could effectively inhibit tumor growth in both pretreated and therapeutic xenograft models. Similar to targeted 
therapies that tackle a gain-of-function in cancer, such as EGFR inhibitors, the introduction of the antagonist specific to oncomiRNA miR-335 interferes with the oncogenic properties of astrocytoma cells and induces therapeutic responses. This "miRNA targeting therapy" has been given more and more attention and successfully demonstrated in several human diseases [47-50], indicating a potential application of this approach in clinical settings. While our results presented here suggest that antagomir-335 may prove useful in the treatment of astrocytoma, the challenge for this approach will be the successful delivery of the miRNA antagonist to the tumor cells. Local delivery of synthetic antagomir-335 by intratumoral injections resulted in strong inhibition of tumor growth. Nevertheless, this delivery route might be inadequate in a clinical setting as peripheral tumor cells remained present. Therefore, a delivery technology that facilitates universal access to all tumor cells, such as a systemic delivery route, might be needed to make the therapy more efficacious.

\section{Conclusions}

In summary, our present study uncovered an oncogenic function of miR-335 resided on chromosome $7 q 32.2$ that amplified frequently in astrocytoma, which may provide a novel insight to its molecular etiology. This effect may be caused by WNT/PCP signaling inhibition ascribed to the restrain of DAAM1 protein. Of note, miR-335 abrogation displayed notable anti-tumor effects both in vitro and in vivo. Significantly, the anti-tumor effects also extended to human malignant astrocytoma, indicating the evolutionarily conserved function of miR335 and a potential application of targeting miR-335 in the therapy of malignant astrocytoma.

\section{Additional material}

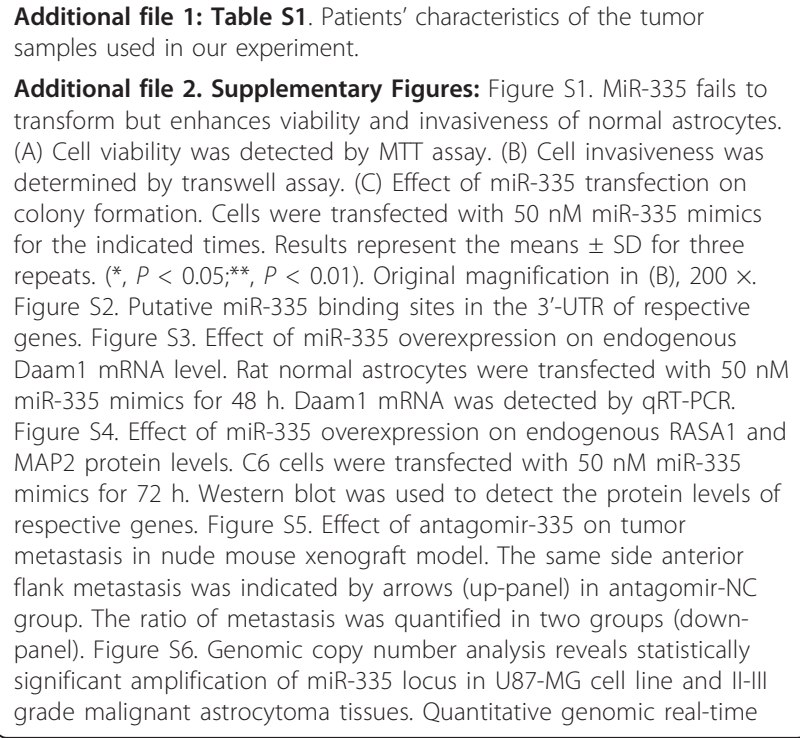

PCR was performed on DNA from HEB, U87-MG cell lines as well as normal brain $(\mathrm{N})$ and II-III grade malignant astrocytoma tissues. Figure 57. MiR-335 expression analysis in human astrocytes HEB and glioblastoma multiform T98G cells. Figure S8. Effect of miR-335 abrogation on cell growth. T98G cells were transfected with $100 \mathrm{nM}$ antagomir-335 for the indicated times. Cell viability was detected with MTT assay. Figure 59 . Effect of miR-335 on Rb1 expression in C6 and U87-MG astrocytoma cells. Cells were transfected with 50 nM miR-335 for $48 \mathrm{~h}$. Rb1 protein was detected by Western blot.

\section{Abbreviations}

miRNA: microRNA; oncomiR: oncogenic miRNA; DAAM1: disheveledassociated activator of morphogenesis 1; siRNA: small interfering RNA; UTR: untranslated region; FBS: fetal bovine serum; GFAP: glial fibrillary acid protein; MTT: 3-(4,5-dimethylthiazol-2-yl)-2,5-diphenyl-tetrazolium bromide; SC: subcutaneous; ROCK: Rho-associated kinase; MLC: myosin light chain; MEST: mesoderm-specific transcript.

\section{Acknowledgements}

We thank Professor Ying Guo for providing human astrocytoma tissues. This work was supported by Key program, National Natural Science Foundation of China (No 30830111), National Natural Science Foundation of China (No 330801408) and National Natural Science Foundation of Guangdong Province (No 8451008901000297).

\section{Authors' contributions}

MS, SW, and XZ contributed equally to this work; MS and GY designed research; MS, SW, XZ, YZ, YL, TL and DX performed research; MS, WZ and GY analyzed data; and MS, HL, WZ, YO, XL, and GY wrote the paper. All authors read and approved the final manuscript.

\section{Competing interests}

The authors declare that they have no competing interests.

Received: 5 October 2010 Accepted: 19 May 2011

Published: 19 May 2011

\section{References}

1. DeAngelis LM: Brain tumors. N Engl J Med 2001, 344:114-123.

2. Gabriely G, Wurdinger T, Kesari S, Esau CC, Burchard J, Linsley PS, Krichevsky AM: MicroRNA 21 promotes glioma invasion by targeting matrix metalloproteinase regulators. Mol Cell Biol 2008, 28:5369-5380.

3. Esquela-Kerscher A, Slack FJ: Oncomirs-microRNAs with a role in cancer. Nat Rev Cancer 2006, 6:259-269.

4. Medina PP, Slack FJ: microRNAs and cancer: an overview. Cell Cycle 2008, 7:2485-2492.

5. Ventura A, Jacks T: MicroRNAs and cancer: short RNAs go a long way. Cell 2009, 136:586-591.

6. Lu J, Getz G, Miska EA, Alvarez-Saavedra E, Lamb J, Peck D, SweetCordero A, Ebert BL, Mak RH, Ferrando AA, et al: MicroRNA expression profiles classify human cancers. Nature 2005, 435:834-838.

7. Dyrskjot L, Ostenfeld MS, Bramsen JB, Silahtaroglu AN, Lamy P, Ramanathan R, Fristrup N, Jensen JL, Andersen CL, Zieger K, et al: Genomic profiling of microRNAs in bladder cancer: miR-129 is associated with poor outcome and promotes cell death in vitro. Cancer Res 2009, 69:4851-4860.

8. Raponi M, Dossey L, Jatkoe T, Wu X, Chen G, Fan H, Beer DG: MicroRNA classifiers for predicting prognosis of squamous cell lung cancer. Cancer Res 2009, 69:5776-5783.

9. Schetter AJ, Leung SY, Sohn JJ, Zanetti KA, Bowman ED, Yanaihara N, Yuen ST, Chan TL, Kwong DL, Au GK, et al: MicroRNA expression profiles associated with prognosis and therapeutic outcome in colon adenocarcinoma. Jama 2008, 299:425-436.

10. Trang P, Medina PP, Wiggins JF, Ruffino L, Kelnar K, Omotola M, Homer R, Brown D, Bader AG, Weidhaas JB, Slack FJ: Regression of murine lung tumors by the let-7 microRNA. Oncogene 2009.

11. Trang P, Weidhaas JB, Slack FJ: MicroRNAs as potential cancer therapeutics. Oncogene 2008, 27(Suppl 2):S52-57. 
12. Holland H, Koschny $T$, Ahnert $P$, Meixensberger J, Koschny R: WHO gradespecific comparative genomic hybridization pattern of astrocytoma-A meta-analysis. Pathol Res Pract 2010.

13. Segura MF, Hanniford D, Menendez S, Reavie L, Zou X, Alvarez-Diaz S, Zakrzewski J, Blochin E, Rose A, Bogunovic D, et al: Aberrant miR-182 expression promotes melanoma metastasis by repressing FOXO3 and microphthalmia-associated transcription factor. Proc Natl Acad Sci USA 2009, 106:1814-1819.

14. Lowery AJ, Miller N, Dwyer RM, Kerin MJ: Dysregulated miR-183 inhibits migration in breast cancer cells. BMC Cancer 2010, 10:502.

15. Yu S, Lu Z, Liu C, Meng Y, Ma Y, Zhao W, Liu J, Yu J, Chen J: miRNA-96 suppresses KRAS and functions as a tumor suppressor gene in pancreatic cancer. Cancer Res 2010, 70:6015-6025.

16. Png KJ, Yoshida M, Zhang XH, Shu W, Lee H, Rimner A, Chan TA, Comen E, Andrade VP, Kim SW, et al: MicroRNA-335 inhibits tumor reinitiation and is silenced through genetic and epigenetic mechanisms in human breast cancer. Genes Dev 2011, 25:226-231.

17. Tavazoie SF, Alarcon C, Oskarsson T, Padua D, Wang Q, Bos PD, Gerald WL, Massague J: Endogenous human microRNAs that suppress breast cancer metastasis. Nature 2008, 451:147-152.

18. Scarola M, Schoeftner S, Schneider C, Benetti R: miR-335 directly targets $\mathrm{Rb} 1$ (pRb/p105) in a proximal connection to p53-dependent stress response. Cancer Res 2010, 70:6925-6933.

19. Tome M, Lopez-Romero P, Albo C, Sepulveda JC, Fernandez-Gutierrez B, Dopazo A, Bernad A, Gonzalez MA: miR-335 orchestrates cell proliferation, migration and differentiation in human mesenchymal stem cells. Cell Death Differ

20. Shu M, Zhou Y, Zhu W, Wu S, Zheng X, Yan G: Activation of a pro-survival pathway IL-6/JAK2/STAT3 contributes to glial fibrillary acidic protein induction during the cholera toxin-induced differentiation of $\mathrm{C} 6$ malignant glioma cells. Mol Oncol 2011.

21. Su H, Yang JR, Xu T, Huang J, Xu L, Yuan Y, Zhuang SM: MicroRNA-101, down-regulated in hepatocellular carcinoma, promotes apoptosis and suppresses tumorigenicity. Cancer Res 2009, 69:1135-1142.

22. Akagi T, Murata K, Shishido T, Hanafusa H: v-Crk activates the phosphoinositide 3-kinase/AKT pathway by utilizing focal adhesion kinase and H-Ras. Mol Cell Biol 2002, 22:7015-7023.

23. Deng J, Miller SA, Wang HY, Xia W, Wen Y, Zhou BP, Li Y, Lin SY, Hung MC: beta-catenin interacts with and inhibits NF-kappa B in human colon and breast cancer. Cancer Cell 2002, 2:323-334

24. Soltani MH, Pichardo R, Song Z, Sangha N, Camacho F, Satyamoorthy K, Sangueza OP, Setaluri V: Microtubule-associated protein 2, a marker of neuronal differentiation, induces mitotic defects, inhibits growth of melanoma cells, and predicts metastatic potential of cutaneous melanoma. Am J Pathol 2005, 166:1841-1850.

25. Astolfi A, Nannini M, Pantaleo MA, Di Battista M, Heinrich MC, Santini D, Catena F, Corless CL, Maleddu A, Saponara M, et al: A molecular portrait of gastrointestinal stromal tumors: an integrative analysis of gene expression profiling and high-resolution genomic copy number. Lab Invest 2010.

26. Stupp R, Mason WP, van den Bent MJ, Weller M, Fisher B, Taphoorn MJ, Belanger K, Brandes AA, Marosi C, Bogdahn U, et al: Radiotherapy plus concomitant and adjuvant temozolomide for glioblastoma. $N$ Engl J Med 2005, 352:987-996

27. Lefranc F, Brotchi J, Kiss R: Possible future issues in the treatment of glioblastomas: special emphasis on cell migration and the resistance of migrating glioblastoma cells to apoptosis. J Clin Oncol 2005, 23:2411-2422

28. Calin GA, Croce CM: MicroRNAs and chromosomal abnormalities in cancer cells. Oncogene 2006, 25:6202-6210.

29. Asangani IA, Rasheed SA, Nikolova DA, Leupold JH, Colburn NH, Post S, Allgayer $\mathrm{H}$ : MicroRNA-21 (miR-21) post-transcriptionally downregulates tumor suppressor Pdcd4 and stimulates invasion, intravasation and metastasis in colorectal cancer. Oncogene 2008, 27:2128-2136.

30. Silber J, James CD, Hodgson JG: microRNAs in gliomas: small regulators of a big problem. Neuromolecular Med 2009, 11:208-222.

31. Marsh EE, Lin Z, Yin P, Milad M, Chakravarti D, Bulun SE: Differential expression of microRNA species in human uterine leiomyoma versus normal myometrium. Fertil Steril 2008, 89:1771-1776.

32. Ronchetti D, Lionetti M, Mosca L, Agnelli L, Andronache A, Fabris S, Deliliers GL, Neri A: An integrative genomic approach reveals coordinated expression of intronic miR-335, miR-342, and miR-561 with deregulated host genes in multiple myeloma. BMC Med Genomics 2008, 1:37.

33. Uziel T, Karginov FV, Xie S, Parker JS, Wang YD, Gajjar A, He L, Ellison D, Gilbertson RJ, Hannon G, Roussel MF: The miR-17 92 cluster collaborates with the Sonic Hedgehog pathway in medulloblastoma. Proc Natl Acad Sci USA 2009, 106:2812-2817.

34. Wang $Y X$, Zhang $X Y$, Zhang BF, Yang CQ, Chen XM, Gao HJ: Initial study of microRNA expression profiles of colonic cancer without lymph node metastasis. J Dig Dis 2010, 11:50-54.

35. Asai A, Miyagi Y, Sugiyama A, Gamanuma M, Hong SH, Takamoto S, Nomura K, Matsutani M, Takakura K, Kuchino Y: Negative effects of wildtype p53 and s-Myc on cellular growth and tumorigenicity of glioma cells. Implication of the tumor suppressor genes for gene therapy. $J$ Neurooncol 1994, 19:259-268.

36. Zupanska A, Dziembowska M, Ellert-Miklaszewska A, Gaweda-Walerych K, Kaminska B: Cyclosporine a induces growth arrest or programmed cell death of human glioma cells. Neurochem Int 2005, 47:430-441.

37. Vasudevan S, Tong Y, Steitz JA: Switching from repression to activation: microRNAs can up-regulate translation. Science 2007, 318:1931-1934.

38. Bhattacharyya SN, Habermacher R, Martine U, Closs El, Filipowicz W: Relief of microRNA-mediated translational repression in human cells subjected to stress. Cell 2006, 125:1111-1124.

39. Kedde M, Strasser MJ, Boldajipour B, Oude Vrielink JA, Slanchev K, le Sage C, Nagel R, Voorhoeve PM, van Duijse J, Orom UA, et al: RNA-binding protein Dnd1 inhibits microRNA access to target mRNA. Cell 2007, 131:1273-1286.

40. Li D, Hallett MA, Zhu W, Rubart M, Liu Y, Yang Z, Chen H, Haneline LS, Chan RJ, Schwartz RJ, et al: Dishevelled-associated activator of morphogenesis 1 (Daam1) is required for heart morphogenesis. Development 2011, 138:303-315.

41. Ang SF, Zhao ZS, Lim L, Manser E: DAAM1 is a formin required for centrosome re-orientation during cell migration. PLOS One 2010, 5.

42. LaMonica K, Bass M, Grabel L: The planar cell polarity pathway directs parietal endoderm migration. Dev Biol 2009, 330:44-53.

43. Ju R, Cirone P, Lin S, Griesbach H, Slusarski DC, Crews CM: Activation of the planar cell polarity formin DAAM1 leads to inhibition of endothelial cell proliferation, migration, and angiogenesis. Proc Natl Acad Sci USA 2010.

44. Salhia B, Rutten F, Nakada M, Beaudry C, Berens M, Kwan A, Rutka JT: Inhibition of Rho-kinase affects astrocytoma morphology, motility, and invasion through activation of Rac1. Cancer Res 2005, 65:8792-8800.

45. Shi J, Wei L: Rho kinase in the regulation of cell death and survival. Arch Immunol Ther Exp (Warsz) 2007, 55:61-75.

46. Song $Y$, Hoang BQ, Chang DD: ROCK-II-induced membrane blebbing and chromatin condensation require actin cytoskeleton. Exp Cell Res 2002, 278:45-52

47. Care A, Catalucci D, Felicetti F, Bonci D, Addario A, Gallo P, Bang ML, Segnalini $P, G u$ Y, Dalton ND, et al: MicroRNA-133 controls cardiac hypertrophy. Nat Med 2007, 13:613-618

48. Thum T, Gross C, Fiedler J, Fischer T, Kissler S, Bussen M, Galuppo P, Just S, Rottbauer W, Frantz $S$, et al: MicroRNA-21 contributes to myocardial disease by stimulating MAP kinase signalling in fibroblasts. Nature 2008 456:980-984

49. Felicetti F, Errico MC, Bottero L, Segnalini P, Stoppacciaro A, Biffoni M, Felli N, Mattia G, Petrini M, Colombo MP, et al: The promyelocytic leukemia zinc finger-microRNA-221/-222 pathway controls melanoma progression through multiple oncogenic mechanisms. Cancer Res 2008, 68:2745-2754.

50. Fontana L, Fiori ME, Albini S, Cifaldi L, Giovinazzi S, Forloni M, Boldrini R, Donfrancesco A, Federici V, Giacomini P, et al: Antagomir-17-5p abolishes the growth of therapy-resistant neuroblastoma through p21 and BIM. PLoS One 2008, 3:e2236.

doi:10.1186/1476-4598-10-59

Cite this article as: Shu et al:: Targeting oncogenic miR-335 inhibits growth and invasion of malignant astrocytoma cells. Molecular Cancer 2011 10:59 